\title{
Corruption Governance and Enterprise Performance: a Lubricant or a Stumbling Block
}

\author{
Fengli He * \\ School of Management \\ Sichuan Agricultural University \\ Chengdu, China \\ annyhe0529@163.com
}

\author{
Liang Zhang \\ School of Management \\ Sichuan Agricultural University \\ Chengdu, China \\ zlcn117@163.com
}

\begin{abstract}
This paper empirically examines the impact of corruption governance on enterprise performance by taking ashare companies in Shanghai and Shenzhen stock exchanges from 2013 to 2017 as samples. The results show that there is a ushaped relationship between corruption governance and enterprise performance; that is, a certain degree of corruption governance is the "stumbling block" of enterprise performance, but a higher degree of corruption governance is the "lubricant" of enterprise performance. In addition, the study also found that under different property rights, the impact of corruption governance on enterprise performance has significant differences.
\end{abstract}

Keywords-corruption governance; enterprise performance; nature of property rights; $u$-shaped relationship

\section{INTRODUCTION}

China's legal system is relatively weak and some administrative rules are vague, which create conditions for corrupt activities. The 18th national congress of the communist party of China clearly proposed to "adhere to the path of anticorruption", followed by a series of regulations on anticorruption, which have brought huge influence to the political, economic and social fields. Therefore, how to effectively punish corruption increasingly brought to the attention of the government regulators, and how to improve enterprise performance through anti-corruption, promote the development of market economy have become the important research topic.

\section{THEORETICAL ANALYSIS AND RESEARCH HYPOTHESIS}

\section{A. Corruption Governance and Enterprise Performance}

Many literatures have investigated the influence of corruption on enterprise performance, and there is a debate between "effective corruption" and "harmful corruption". But "effective corruption" mostly stays in the theoretical level, in reality, anti-corruption is the inevitable choice of political civilization and economic development. After the 18th national congress, the government issued a series of anti-corruption regulations, and the anti-corruption campaign is in a highpressure situation. Once officials were imprisoned for corruption, the good relationship between officials and enterprises would be cut off, and related enterprises would lose their protection, which would have a huge impact on their development. It can be seen that in the early stage of anticorruption, the anti-corruption action broke the original steadystate equilibrium of the relationship between government and enterprise, but it could not be transferred to the new steadystate equilibrium in a short time, which may lead to the shortterm decline of enterprise performance. However, with the strengthening of anti-corruption, its positive impact on enterprise performance has become prominent. On the one hand, long-term corruption governance has created a more positive operating environment for enterprises [1]. On the other hand, higher degree of corruption governance can effectively reduce earning management, which improves corporate governance environment, and enhances corporate value [2]. Therefore, hypothesis 1 is proposed:

Hypothesis 1: there is a u-shaped relationship between corruption governance and enterprise performance, that is, a certain degree of corruption governance will reduce enterprise performance, but a higher degree of corruption governance can improve enterprise performance.

\section{B. The Nature of Property Rights}

For state-owned enterprises, there is a u-shaped relationship between corruption governance and enterprise performance. In the early stage of anti-corruption, corruption governance will reduce the performance of state-owned enterprises, because the executives of state-owned enterprises usually keep close contact with officials. However, powerful anti-corruption policies have led to the imprisonment of a large number of corrupt officials and cut off the access of state-owned enterprises to get social resources, resulting in greater impact on state-owned enterprises. With a higher degree of corruption governance, the positive impact of performance of state-owned enterprises begins to emerge. A short office term, the variable state executive and the lack of salary incentive make enterprises pay more attention to post treatment and political promotion. under the background of political promotion tournament, state-owned enterprises are more inclined to concentrate resources invested in effective achievements project, making the enterprise performance improvement.

For non-state-owned enterprises, there is an inverted ushaped relationship between corruption governance and enterprise performance. The anti-corruption campaign has created a relatively fair political and economic environment for the non-state-owned enterprises, reducing ownership discrimination and administrative exploitation. Therefore, the performance of non-state-owned enterprises will increase significantly in a short time. But on the other hand, under the constraint of limited resources, many non-state-owned 
enterprises that rely on dealing with the government have to adjust. In order to keep stable and lasting competitive advantage, more enterprises inclined to invest in a long-term project, such as the innovation and product market, so the nonstate enterprise performance in a short period of time will be a slight decline. Therefore, hypothesis 2 is proposed:

Hypothesis 2a: for state-owned enterprises, there is a ushaped relationship between corruption governance and enterprise performance.

Hypothesis 2b: for non-state-owned enterprises, there is an inverted u-shaped relationship between corruption governance and enterprise performance.

\section{RESEARCH DESIGN}

\section{A. Sample Selection and Data Sources}

This paper takes the a-share enterprises of Shanghai and Shenzhen stock exchanges from 2013 to 2017 as samples. Excluding the listed companies with missing data and issued A and B shares at the same time, a total of 8,120 observations were obtained for 5 years from 1,624 companies. Data on corruption governance came from the Annual inspection report of People's Procuratorate and China statistical yearbook, and other data came from CSMAR.

\section{B. Variable Definition and Econometric Model}

The variable definitions are shown in TABLE I.

TABLE I. DEFINITION OF VARIABLES

\begin{tabular}{|l|l|l|}
\hline \multirow{2}{*}{ Name } & Variables & Definitions \\
\hline Enterprise performance & ROA & Net profit, average total assets \\
\hline \multirow{2}{*}{ Corruption governance } & AntiCorr & The number of job-related crimes per 10,000 people in each province (city) \\
\cline { 2 - 3 } & AntiCorrsq & The square term of AntiCorr \\
\hline Nature of ownership & OWNER & Dummy variable, soe = 1, otherwise = 0 \\
\hline The company size & SIZE & The log of total assets \\
\hline Operation ability & OPC & Main business income, total assets \\
\hline Cash flow capacity & SCR & Net operating cash flow, main business income \\
\hline Liquidity & LR & Current assets, current liabilities \\
\hline Executive incentive & SALARY & The log of the total compensation of the top three executives \\
\hline Equity structure & SHARE1 & The largest shareholding ratio \\
\hline Checks and balances structure & SHARE2 & Shareholding ratio of the second to the tenth, the larges \\
\hline Proportion of independent directors & IND_BD & The ratio of independent directors to the size of the board of directors \\
\hline Board size & BDSIZE & Number of directors \\
\hline Listed age & The AGE & The log of listing age \\
\hline Industry variable & INDUSTRY & Dummy variable \\
\hline The annual variable & YEAR & Dummy variable \\
\hline
\end{tabular}

To test the impact of corruption governance on enterprise performance, the model (1) was built:

$$
R O A_{i, t}=\alpha_{0}+\alpha_{1} \text { AntiCorr }_{i, t}+\alpha_{2} \text { AntiCorrsq }_{i, t}+\alpha_{i} \text { Controls }_{i, t}+\varepsilon_{i, t}(1)
$$

To test the interactive influence of the nature of property rights and corruption governance on enterprise performance, the model (2) was built:

$$
\begin{aligned}
& \text { ROA }_{1, \mathrm{t}}=\alpha_{0}+\alpha_{1} \text { AntiCorr }_{i, t}+\alpha_{2} \text { AntiCorrsq }_{i, t}+\alpha_{3} \text { OWNER }+ \\
& \alpha_{4} \text { AntiCorr }_{i, t} * \text { OWNER }+\alpha_{5} \text { AntiCorrsq }_{i, t} * \text { OWNER }+\alpha_{i} \text { Controls }_{i, t}+\varepsilon_{i, t}
\end{aligned}
$$

\section{EMPIRICAL TEST AND ANALYSIS}

\section{A. Descriptive Statistics}

Descriptive statistics are shown in TABLE II. The lower quartile of enterprise performance ROA is 0.01 , the mean is 0.03 , and the difference between the mean and the lower quartile (0.02) is less than the difference between the mean and the upper quartile (0.03), showing a significant right-skewed distribution, indicating that there are more enterprises with low profitability. The maximum value, minimum value and standard deviation of AntiCorr was 0.79, 0.17 and 0.12, indicating that corruption governance in different regions was significantly different. From the perspective of mean, standard deviation and median of control variables, the difference between mean and median is very small, and the difference between the upper, lower quartile and the median of each indicator is also small, indicating that the data is normally distributed.

TABLE II. DESCRIPTIVE STATISTICS OF VARIABLES

\begin{tabular}{|l|c|c|c|c|c|c|c|}
\hline Variable & $\mathbf{N}$ & Mean & sd & p25 & p75 & Min & Max \\
\hline ROA & 8120 & 0.03 & 0.05 & 0.01 & 0.06 & 0.17 & 0.18 \\
\hline AntiCorr & 8120 & 0.33 & 0.12 & 0.25 & 0.38 & 0.17 & 0.79 \\
\hline AntiCorrsq & 8120 & 0.12 & 0.10 & 0.06 & 0.14 & 0.03 & 0.63 \\
\hline SIZE & 8120 & 22.24 & 1.19 & 21.41 & 22.96 & 19.69 & 25.68 \\
\hline OPC & 8120 & 0.58 & 0.40 & 0.32 & 0.72 & 0.05 & 2.24 \\
\hline SCR & 8120 & 0.08 & 0.22 & 0.01 & 0.17 & 0.99 & 0.75 \\
\hline LR & 8120 & 2.29 & 2.31 & 1.08 & 2.56 & 0.25 & 15.38 \\
\hline SALARY & 8120 & 14.29 & 0.66 & 13.86 & 14.68 & 12.69 & 16.14 \\
\hline SHARE1 & 8120 & 34.40 & 14.79 & 22.60 & 44.50 & 8.80 & 72.88 \\
\hline SHARE2 & 8120 & 0.83 & 0.73 & 0.28 & 1.17 & 0.04 & 3.52 \\
\hline IND - BD & 8120 & 0.37 & 0.05 & 0.33 & 0.43 & 0.33 & 0.57 \\
\hline BDSIZE & 8120 & 8.68 & 1.70 & 7 & 9 & 5 & 15 \\
\hline The AGE & 8120 & 2.22 & 0.74 & 1.61 & 2.83 & 0 & 3.18 \\
\hline
\end{tabular}

\section{B. Corruption Governance and Enterprise Performance}

Regression was performed on model (1), and the results are shown in columns (1) to (3) of TABLE III. Column (1) considered the impact of corruption governance on enterprise performance, and the results showed that the primary coefficient of corruption governance was significantly negative at the $1 \%$ level. In economies with imperfect systems and mechanisms, corruption governance is likely to break the good stable relationship between government and enterprises, resulting in the decline of enterprise performance, but this is 
also the prerequisite for the formation of a new stable relationship promoting enterprise development. In column (2), it is found that the coefficients of the primary term and the secondary term of corruption governance are significantly negative and positive at $1 \%$ level respectively, indicating that a certain degree of corruption governance has a negative effect on enterprise performance, while a higher degree of corruption governance has a positive effect on enterprise performance. Column (3) adds control variables and the conclusion remains unchanged. This finding is different from the simple linear relationship believed in the existing literature. This paper shows that corruption governance and enterprise performance is a u-shaped non-linear relation, that is, hypothesis (1) is verified.

To further clarify the relationship, the inflection point of the quadratic curve was calculated as 0.5052 using the results of column (3), which was slightly less than the 95\% quantile (0.5504). It means about 5\% of corruption governance data were located at the right side of the inflection point, indicating that the relationship between corruption governance and enterprise performance presented an asymmetric u-shaped curve of slow left and steep right, falling first and then rising. One possible explanation is that the effective market economic has not yet been established, so stable relationship of corruption may help the enterprise production and business operation smoothly, yet the initial anti-corruption action broke the stability of this relationship and new relations has not form, thus can make the performance decline, and as a result of the corruption secretive and anti-corruption policy lag effect, the downturn is relatively slow. However, when the corruption governance reaches a certain level, the government functions are further optimized and the market mechanism of fairness and justice is gradually formed, which creates a favorable external environment for improving the performance of enterprises [3]. At the same time, anti-corruption cuts off the possibility for enterprises to seek development through rentseeking [4], so that enterprises can invest more resources in productive activities and improve the marginal growth rate of enterprise performance [5]. In addition, the symbols of the control variables are as expected and because of space limit, we are not described here.

TABLE III. REGRESSION RESULTS

\begin{tabular}{|c|c|c|c|c|c|c|}
\hline Variables & (1) All samples & (2) All samples & (3) All samples & (4) Soe & (5) Non-soe & (6) Interactive items \\
\hline \multirow[b]{2}{*}{ AntiCorr } & $-0.0429 * * *$ & $-0.123^{* * *}$ & $-0.0487 * *$ & $-0.0989 * * *$ & 0.0269 & $-0.160 * * *$ \\
\hline & $(0)$ & $(0)$ & $(-0.0144)$ & $(-0.00378)$ & $(-0.276)$ & $(0)$ \\
\hline \multirow{2}{*}{ AntiCorrsq } & & $0.0945^{* * *}$ & $0.0482 * *$ & $0.0982 * *$ & -0.0285 & $0.158 * * *$ \\
\hline & & $(-0.000183)$ & $(-0.0349)$ & $(-0.0119)$ & $(-0.314)$ & $(-0.00003)$ \\
\hline \multirow{2}{*}{ OWNER } & & & & & & $0.0333^{* * *}$ \\
\hline & & & & & & $(-0.00003)$ \\
\hline \multirow{2}{*}{ OWNER*AntiCorr } & & & & & & $0.182 * * *$ \\
\hline & & & & & & $(-0.00001)$ \\
\hline \multirow{2}{*}{ OWNER*AntiCorrsq } & & & & & & $-0.179 * * *$ \\
\hline & & & & & & $(-0.000134)$ \\
\hline \multirow{2}{*}{ SIZE } & & & $0.00147 * *$ & 0.000937 & $0.00237 * * *$ & $0.00166 * * *$ \\
\hline & & & $(-0.0108)$ & $(-0.333)$ & $(-0.00109)$ & $(-0.00397)$ \\
\hline \multirow{2}{*}{ OPC } & & & $0.0238 * * *$ & $0.0136^{* * *}$ & $0.0324 * * *$ & $0.0242 * * *$ \\
\hline & & & $(0)$ & (0) & $(0)$ & (0) \\
\hline \multirow{2}{*}{ SCR } & & & $0.0439 * * *$ & $0.0318^{* * *}$ & $0.0485^{* * *}$ & $0.0439 * * *$ \\
\hline & & & (0) & (0) & (0) & (0) \\
\hline \multirow{2}{*}{ LR } & & & $0.00437 * * *$ & $0.00720^{* * * *}$ & $0.00384 * * *$ & $0.00432 * * *$ \\
\hline & & & (0) & $(0)$ & (0) & (0) \\
\hline \multirow{2}{*}{ SALARY } & & & $0.0159 * * *$ & $0.0208^{* * *}$ & $0.0133^{* * *}$ & $0.0153^{* * *}$ \\
\hline & & & (0) & (0) & (0) & (0) \\
\hline \multirow{2}{*}{ SHARE1 } & & & $0.000489 * * *$ & $0.000551^{* * *}$ & $0.000429^{* * *}$ & $0.000509^{* * *}$ \\
\hline & & & $(0)$ & (0) & $(0)$ & (0) \\
\hline \multirow{2}{*}{ SHARE2 } & & & $0.00622 * * *$ & $0.00526 * * *$ & $0.00502^{* * *}$ & $0.00615^{* * *}$ \\
\hline & & & $(0)$ & $(-0.00802)$ & $(0)$ & $(0)$ \\
\hline \multirow{2}{*}{ IND_BD } & & & $-0.0377 * * *$ & $-0.0400 * *$ & $-0.0237 *$ & $-0.0337 * * *$ \\
\hline & & & $(-0.000674)$ & $(-0.0291)$ & $(-0.0964)$ & $(-0.00234)$ \\
\hline \multirow{2}{*}{ BDSIZE } & & & $-0.000905^{* *}$ & -0.000132 & -0.000648 & $-0.000704 *$ \\
\hline & & & $(-0.0124)$ & $(-0.809)$ & $(-0.197)$ & $(-0.0532)$ \\
\hline \multirow{2}{*}{ AGE } & & & $-0.00692^{* * *}$ & -0.00248 & $-0.00728^{* * *}$ & $-0.00594^{* * *}$ \\
\hline & & & (0) & $(-0.233)$ & (0) & (0) \\
\hline \multirow{2}{*}{ Constant } & $0.0376 * * *$ & $0.0535 * * *$ & $-0.230 * * *$ & $-0.314 * * *$ & $-0.219 * * *$ & $-0.244 * * *$ \\
\hline & $(0)$ & $(0)$ & $(0)$ & $(0)$ & $(0)$ & (0) \\
\hline Adjusted R-squared & 0.0918 & 0.0933 & 0.2604 & 0.2966 & 0.2611 & 0.2641 \\
\hline $\mathrm{N}$ & 8120 & 8120 & 8120 & 2750 & 5370 & 8120 \\
\hline $\mathrm{F}$ & 11.39 & 11.44 & 32.77 & 15.68 & 23.32 & 32.34 \\
\hline
\end{tabular}

\section{The Influence under Different Property Rights}

In order to verify hypothesis 2 , this paper divides the whole sample into state-owned enterprises and non-state-owned enterprises, and the results are shown in TABLE III column (4) and (5). Column (4) examines the impact of corruption governance on the performance of state-owned enterprises. The results show that the primary term coefficient of corruption governance is significantly negative at $1 \%$ level and the 
secondary term coefficient is significantly positive at 5\% level, indicating a u-shaped relationship between corruption governance and the performance of state-owned enterprises, which verifies hypothesis $2 \mathrm{a}$. Column (5) considers the impact of corruption governance on the performance of non-stateowned enterprises, and the results are not significant, so hypothesis $2 \mathrm{~b}$ is rejected. The reason may be that non-stateowned enterprises operate completely in accordance with the market rules and take the maximization of enterprise value as the goal. Their internal governance mechanisms, such as incentive, assessment and supervision, are relatively perfect, and the probability of corruption is low [6]. In turn, corruption governance has a weak impact on the production and operation of non-state-owned enterprises.

In addition to grouping test, this paper also used model (2) to test the interactive impact of the nature of property rights and corruption governance on enterprise performance. The results are shown in TABLE III (6). Results show that in 1\% of the level, OWNER*AntiCorr has a significant positive effect on enterprise performance, and OWNER*AntiCorrsq has a significant negative effect on enterprise performance, this suggests that the nature of property rights has an inverted ushaped regulating effect on the u-shaped relationship between corruption governance and enterprise performance. Using column (7), we calculate the inflection point of u-shaped relationship is 0.5063 , and the inflection point of the inverted u-shaped regulating effect is 0.5084 , combined with the TABLE II shows the corruption governance level of minimum and maximum were 0.17 and 0.79 . For the state-owned enterprises, when corruption governance in 0.17 to 0.5063 , the performance of state-owned enterprises falling speed is slower. When the level of corruption governance is between 0.5063 and 0.5084 , the performance of state-owned enterprises will temporarily accelerate. When the level of corruption governance is between 0.5084 and 0.79 , the rising speed slows down.

\section{ROBUSTNESS TEST}

In order to ensure the reliability of the research results, the following robustness tests were conducted in this paper: (1) in recent years, "collapse mode" corruption occurred in Sichuan, Chongqing, so we examine the impact of corruption governance on enterprise performance in western regions, and the conclusion remains. (2) ROE and ROS are used to represent enterprise performance respectively, and the number of corruption cases per 10,000 people in each province (city) is used to represent corruption governance, and the conclusion remains.

\section{CONCLUSIONS AND SUGGESTIONS}

Against the background of anti-corruption in the 18th CPC national congress, this paper examines the influence of corruption governance on microeconomic individuals. Research findings: (1) there is a significant u-shaped relationship between corruption governance and enterprise performance [7]. (2) under different property rights, the influence of corruption governance on enterprise performance is significantly different, Moreover, the nature of property rights has an inverted u-shaped regulating effect on the ushaped relationship between corruption governance and enterprise performance.

The policy implications of this paper are as follows :(1) in the long run, higher intensity of corruption governance is the "lubricant" of enterprise operation and development. Therefore, cracking down on the breeding and spreading of corruption is the driving force for enterprise performance improvement. (2) bribery and other corrupt activities are undoubtedly the result of distorted market, which needs to correctly handle the relationship between the government and the market to promote the healthy development of listed companies and the capital market.

\section{REFERENCES}

[1] Bailey, D. H. The Effect of Corruption on FDI: A Parametric and nonparametric Analysis[J]. European Journal of Political Economy.2012, (28):302-312.

[2] Li Houjian, Zhang Jian. Corruption and enterprise innovation: lubricant or stumbling block. [J]. Nankai economic research.2015, (2):24-58. (In Chinese)

[3] Li Shigang, Yin Heng. How much is the social cost of talent misprision caused by rent-seeking? [J]. Economic research, 2014, (7):56-66. (In Chinese)

[4] Xu Xixiong, Liu Xing. Decentralization reform, salary control and corporate executive corruption [J]. Management world, 2013, (3):119132. (In Chinese)

[5] Zhan Lei, Wang Yaoyao. Management incentives, overinvestment and enterprise value [J]. Nankai management review, 2013 (03):36-46. (In Chinese)

[6] Zhong Qinlin, Lu Zhengfei, Yuan Chun. Anti-corruption, enterprise performance and its channel effect-based on the anti-corruption construction of the 18th CPC national congress [J]. Financial research, 2016, (9): 161-176. (In Chinese)

[7] Zhou Meihua, Lin Bin, Lin Dongjie. Management power, internal control and corruption governance [J]. Accounting Research, 2016, (3): 56-63, 96. (In Chinese) 